\title{
Necessidade de estrutura de compliance nas instituições financeiras
}

Elaine Aparecida Maruyama Vieira Nakamura

Doutoranda em Administração na Universidade Nove de Julho UNINOVE. Programa de Pós Graduação em Administração - PPGA da UNINOVE

elaine.vieira.nakamura@gmail.com

Wilson Toshiro Nakamura

Professor do PPGA da Universidade Presbiteriana Mackenzie

Doutor em Administração pela Universidade de São Paulo

wtnakamura@uol.com.br

Graciela Dias Coelho Jones

Docente do Núcleo de Contabilidade Gerencial e Finanças da Faculdade de Ciências Contábeis na Universidade Federal de Uberlândia (UFU).

Doutora em Administração, pela Universidade Presbiteriana Mackenzie

graciela.jones@ufu.br

\section{Editor Científico: José Edson Lara}

Organização Comitê Científico

Double Blind Review pelo SEER/OJS

Recebido em 20.08.2019

Aprovado em 08.11.2019

Este trabalho foi licenciado com uma Licença Creative Commons - Atribuição - Não Comercial 3.0 Brasil 


\title{
Resumo
}

Fundamento do estudo: a área de Compliance é muito importante, principalmente para Instituições Financeiras, sendo responsável por instituir controles, regras, procedimentos preventivos em atendimento aos regulamentos e legislações nacionais e internacionais. Essa área representa uma extensão nas Instituições, em atendimento a legislação de prevenção à lavagem de dinheiro (monitoramento das movimentações financeiras), e tem forte importância como pilar de Governança Corporativa.

Objetivo do estudo: o objetivo desse relato técnico é descrever de forma aplicada a evolução da área de Compliance, sua importância, sua abrangência, as contribuições da existência de adequada estrutura às necessidades da Instituição e do mercado e as consequências de não ter a área.

Metodologia: Este estudo foi baseado na experiência de 13 anos, na estruturação das responsabilidades de uma área de Compliance, por meio de participação direta em uma Instituição Financeira,

Resultados: tudo o que é relatado confirma que organizações necessariamente precisam buscar o compliance, como meio de fortalecer sua posição no mercado, e encarar a ética não só como uma forma de ação conveniente. Após anos de experiência na área, desenvolvendo-a e estruturando-a, conclui-se que compliance é um braço dos Órgãos Reguladores junto a Administração, no que se refere à segurança, respeito à normas e controles e à busca da conformidade por meio da ética.

Palavras-chave: Compliance. Regulamentação. Sanções financeiras. Instituição Financeira.

\section{Need for compliance structure in financial institutions}

\begin{abstract}
Basis of the study: The Compliance area is very important, especially for Financial Institutions, being responsible for instituting controls, rules, preventive procedures in compliance with national and international regulations and laws. This area represents an extension in the Institutions, in compliance with money laundering prevention legislation (monitoring of financial movements), and has strong importance as a pillar of Corporate Governance.

Objective of the study: The purpose of this technical report is to describe in an applied way the evolution of the Compliance area, its importance, its scope, the contributions of the existence of an adequate structure to the needs of the Institution and the market and the consequences of not having the area.
\end{abstract}

Methodology: This study was based on 13 years of experience in structuring the responsibilities of a Compliance area through direct participation in a Financial Institution.

Results: All that is reported confirms that organizations necessarily need to pursue compliance as a means to strengthen their market position and to view ethics not only as a convenient form 
of action. After years of experience in the area, developing and structuring it, it is concluded that compliance is an arm of the Regulatory Bodies with the Administration, regarding safety, compliance with rules and controls and the pursuit of compliance through ethic.

Keywords: Compliance. Regulation. Financial sanctions. Financial institution.

\section{Necesidad de estructura de compliance en instituciones financieras}

\section{Resumen}

Base del estudio: el área de Cumplimiento es muy importante, especialmente para las Instituciones Financieras, ya que es responsable de instituir controles, normas y procedimientos preventivos de conformidad con las regulaciones y leyes nacionales e internacionales. Esta área representa una extensión en las Instituciones, en cumplimiento de la legislación de prevención de lavado de dinero (monitoreo de movimientos financieros), y tiene una gran importancia como pilar del Gobierno Corporativo.

Objetivo del estudio: El propósito de este informe técnico es describir de manera aplicada la evolución del área de Cumplimiento, su importancia, su alcance, las contribuciones de la existencia de una estructura adecuada a las necesidades de la Institución y el mercado y Las consecuencias de no tener el área.

Metodología: este estudio se basó en 13 años de experiencia en la estructuración de las responsabilidades de un área de cumplimiento mediante la participación directa en una institución financiera.

Resultados: Todo lo que se informa confirma que las organizaciones necesariamente necesitan buscar el cumplimiento como un medio para fortalecer su posición en el mercado y ver la ética no solo como una forma conveniente de acción. Después de años de experiencia en el área, desarrollándola y estructurándola, se concluye que el cumplimiento es un brazo de los Organismos Reguladores con la Administración, con respecto a la seguridad, el cumplimiento de las normas y controles y la búsqueda del cumplimiento a través de la ética.

Palabras clave: Cumplimiento. Reglamento Sanciones financieras. Institución financiera

\section{Introdução}

O Compliance nas empresas originou-se nas instituições financeiras, com a criação do Banco Central Americano, em 1913, que teve como objetivo a formação de um sistema financeiro mais flexível, seguro e estável, e, logo após a quebra da Bolsa de Nova York de 1929, foi criada a Política Intervencionista New Deal, em uma tentativa de intervir na economia para "corrigir as distorções naturais do capitalismo"(Manzi, 2008, p. 27). 
No Brasil, somente a partir de 1992, o compliance teve sua abertura comercial incrementada nacionalmente, quando procurou se alinhar com o mercado mundial, em busca de melhorar suas condições de competitividade e, simultaneamente, a implementação de novas regras de segurança para as instituições financeiras.

No âmbito internacional "estar em Compliance" é o mínimo esperado perante às normas de conduta e exigências legais, e também porque, por muito mais tempo o tema vem sendo difundido. No Brasil, ainda existe um campo amplo para ser explorado em termos de pesquisa sobre o tema.

O objetivo desse relato técnico é descrever de forma aplicada a evolução histórica da área de Compliance, sua importância, sua abrangência, as contribuições da existência de adequada estrutura às necessidades da Instituição e do mercado. Adicionalmente, são apresentadas as consequências da não existência da área de compliance implementada nas organizações.

O presente estudo foi desenvolvido na Diretoria de Compliance de uma instituição financeira multinacional de grande porte, de origem Holandesa, com sede no Brasil, localizada na cidade de São Paulo. Até final de 2008, quando da sua venda, foi o quarto maior banco de varejo do país, com mais de 33 mil colaboradores. A instituição tem como estratégia e valores colocar sempre os clientes em primeiro lugar, e como meta criar valor de maneira sustentável e a longo prazo para todos os envolvidos, como clientes, acionistas, funcionários e a sociedade de maneira geral.

Com base em experiência presencial, por meio da observação direta e a participação direta dentro da Instituição Financeira, desde o início da implemnetação da área de Compliance, o presente relato mostra que a área de compliance não se limita a adoção de medidas de vigilância regulatória, mas também se integra com assuntos e outras áreas da Instituição, atentando para questões como valores éticos, sustentabilidade, inovação, que buscam neutralizar fatos ilícitos e incentivar culturas de grupo, buscando uma prevenção geral positiva, no sentido de fomentar os valores ético-sociais da ação como via de proteção dos bens.

O relato técnico é apresentado em 5 seções, a começar pela Introdução. Na seção 2, temse o referencial teórico, disposto da seguinte forma: Na seção 2.1 são apresentados os aspectos gerais e histórico, na seção 2.2, a importância da área de Compliance. Continuando, na seção 3, é apresentada a metodologia, na seção 4 discute-se os resultados obtidos e análise. Por fim, na seção 5 , tem-se as considerações finais sobre o relato técnico. 


\section{Referencial Teórico}

\subsection{Aspectos gerais e Histórico}

Compliance significa "Cumprir", "Executar", "Satisfazer", "Realizar o que the foi imposto" ou seja, Compliance é o dever de cumprir, de estar em conformidade e fazer cumprir regulamentos internos e externos impostos às atividades da Instituição.

Nesse sentido, estar em compliance é estar em conformidade com leis e regulamentos internos e externos; é, acima de tudo, uma obrigação individual de cada colaborador dentro da Instituição. Quanto ao risco de Compliance, pode-se afirmar que consiste basicamente no risco de sanções legais ou regulatórias, de perda financeira ou de reputação que uma instituição financeira pode sofrer como resultado da falha no cumprimento da aplicação de leis, regulamentos, código de conduta e das Boas Práticas Bancárias.

Em sua missão, programas de Compliance, visam assegurar, em conjunto com as demais áreas, a adequação, o fortalecimento e o funcionamento do Sistema de Controles Internos da Instituição, procurando mitigar os riscos, de acordo com a complexidade de seus negócios, bem como disseminar a cultura de controles para assegurar o cumprimento de leis e regulamentos existentes.

Em 1985, criou-se nos EUA a Comissão Nacional sobre Fraudes em relatórios financeiros, uma iniciativa independente, para estudar as causas de ocorrência de fraudes em relatórios financeiros. Em 1992, publicaram o trabalho de Controles Internos - um modelo integrado, tornando-se referência mundial para o estudo e aplicação dos controles internos. Posteriormente, a comissão passou a ser Comitê, chamado de COSO (Comitê das organizações patrocinadoras), que trabalha de forma independente em relação a suas entidades patrocinadoras. É patrocinado por cinco das principais associações de classe de profissionais ligados à área financeira nos EUA (Tarantino, 2006).

Segundo a Associação Brasileira de Bancos Internacionais (ABBI), à partir de 1992, o Brasil teve sua abertura comercial incrementada nacionalmente, quando procurou se alinhar com o mercado mundial, em busca de majorar suas condições de competitividade e, simultaneamente, possibilitar a implementação de novas regras de segurança para as instituições financeiras, a fim de gerar a adesão do mercado interno às boas práticas financeiras, em obediência ao determinado pelo Comitê da Basiléia para Supervisão Bancária.

Desde meados dos anos 90, diversos casos de fraude financeira têm ocorrido, como exemplo o caso do Banco Barings em 1995. Esse evento aconteceu devido ao acúmulo das 
funções centralizadas no trader que também era chefe do backoffice, e ao desconhecimento das atividades e a falta de controles pelos superiores. Outros casos são o do Banco Societé Generale de 2008, Daiwa, Sumitomo Corporation e Amaranth.

A consequência comum entre os bancos que quebraram foi a intensificação de debates acerca do gerenciamento de riscos sobre instituições financeiras, logo após a ocorrência das fraudes, além de comparações com outros casos semelhantes causados por "rogue traders". (Silva, 2008, p. 41).

O Banco Central do Brasil entendeu a necessidade de se adequar ao mundo e criar a sua Resolução $n^{\circ}$ 2554/98, que determina principalmente a implantação e implementação de um Sistema de Controles Internos em seus sistemas de informações financeiras, operacionais e gerenciais, além do cumprimento das normas legais e regulamentares. No seu artigo $4^{\circ}$, incube a diretoria da instituição, a promoção de elevados padrões éticos e de integridade e de uma cultura organizacional que demonstre e enfatize, a todos os funcionários, a importância dos controles internos e o papel de cada um no processo, ou seja, a disseminação dessa cultura de controles e o estabelecimento de representantes de áreas para acompanhamento (BACEN, 2015).

Entende-se que a base da Resolução sobre controles foi primordial para a criação da área de Compliance, mas aliada fortemente à Lei $\mathrm{n}^{\circ}$ 9613/98, que dispõe sobre os crimes de "lavagem" ou ocultação de bens, direitos e valores, e determina uma estrutura para monitorar as atividades financeiras das pessoas físicas e jurídicas resultando em relatos periódicos ao COAF (Manzi, 2008, p. 30).

O Banco Central do Brasil controla as atividades de instituições financeiras, estabelecendo regras, supervisionando e fiscalizando suas atividades, com o objetivo de criar uma rede de proteção bancária que, por meio de seus instrumentos, busca dar mais segurança e confiança aos investidores.

Assim, nasce a necessidade no Brasil de "construir" uma área que tivesse a visão geral das atividades, fosse preventiva e não corretiva como a Auditoria, não tivesse somente foco em legislação como a área Jurídica, trabalhasse com padrões éticos, morais, sem focar somente nos quesitos de Recursos Humanos, consolidasse os riscos inerentes da Instituição, sem ser a área de riscos operacionais, e tivesse uma independência das demais diretorias para conscientizar a alta administração dos riscos existentes, focar nas ações preventivas e nas adequação dos aspectos de compliance. 
O ataque de 11/09/2001 nos EUA e os escândalos financeiros em Wall Street em 2002 despertaram o mercado financeiro para a necessidade de regulamentações, ainda mais efetivas e rapidamente aplicáveis em todos os países, buscando gerir os riscos aos quais as instituições estão sujeitas, solidificando a necessidade, agora sem volta, de estrutura de controles internos.

Com isso, as instituições financeiras foram compelidas a iniciar um ciclo de mudanças cada vez mais radicais, com reestruturações estratégicas, organizacionais e tecnológicas, dentre as quais o fortalecimento de "Política de Controles Internos" e de "Código de Ética e Normas de Conduta”, denominando-se, em termos gerais, de programas de compliance, que pode ser entendido como a análise criteriosa da adequação dos processos, da cultura e da disciplina organizacional, recursos humanos e tecnologia, e na aplicação de controles rigorosos, preventivos e detectivos no gerenciamento dos Riscos, por meio de uma atuação conjunta com os gestores na avaliação, gestão e monitoração dos mecanismos de medição de informações de desempenho.

Após longos anos de trâmite no Congresso Nacional, veio à tona a Lei Anticorrupção Lei ${ }^{\circ}$ 12.846, de 01.08.2013, que inovou no ordenamento jurídico brasileiro ao trazer em seu bojo uma mudança de perspectiva no combate à corrupção. Ela acresce ao Direito Penal e à perseguição à pessoa física, o Direito Administrativo Sancionador, indo ao encalço da pessoa jurídica. Apesar da tipificação de crime de corrupção na sistemática penal nacional, não havia uma norma que também alcançasse as empresas envolvidas em casos de corrupção, pois a punição positivada dizia respeito, tão somente ao âmbito pessoal.

Atendendo a uma inclinação internacional, a nova lei - Lei Anticorrupção, preenche uma lacuna existente na legislação brasileira ao alcançar a empresa do corruptor, estendendo as punições dos funcionários envolvidos em crimes de corrupção às empresas nas quais trabalham (Bittencourt, 2014, p. 21-22).

\subsection{A importância da área de Compliance}

A missão de uma área de Compliance em uma instituição está voltada a assegurar a existência de políticas e normas, pontos de controle no processo a mitigar riscos, relatórios que visem melhorias nos controles internos e práticas saudáveis para a gestão de riscos operacionais (Laruccia; Yamada, 2013, p. 51). 
Tudo isso, visa garantir a credibilidade frente aos stakeholders e shareholders, de forma transparente, além de propiciar a corporação e a manutenção de suas finanças saudáveis, minimizando os riscos de perdas.

Estar ou não compliance não se confunde com poder ou não atuar no mercado, pois essa liberdade, garantida constitucionalmente, não é - e nem poderia ser - subtraída pela autoregulação ou por qualquer entidade privada tuteladora de normas de auto-regulação livremente adotadas. A decisão declaratória de non compliance tem o objetivo de alertar que certas relações podem afetar a liberdade, a isonomia, a competitividade e a transparência existentes no mercado, uma vez que podem implicar vulnerar regras voluntariamente estabelecidas (CENP, 2014).

Hoje, no Brasil, o compliance é estabelecido com o propósito de estar diretamente ligado às mudanças que visam alinhar processos e assegurar o cumprimento de normas e procedimentos por meio de um efetivo ambiente de controle, além de preservar a boa reputação da Instituição perante o seu mercado. É importante ressaltar que o Compliance vai além das barreiras legais e regulatórias. Compliance agrega valores comportamentais, relacionados à integridade, comprometimento e honestidade de todos os participantes da organização.Não ter uma área de Compliance incorre em riscos inerentes como reputacional, financeiro, criminal e até de continuidade dos negócios (ACREFI, 2010).

Um banco deve assegurar que quaisquer acordos de subcontratação não impeçam uma supervisão eficaz pelos seus supervisores. Independentemente de as tarefas específicas, da função de compliance serem terceirizados, o conselho de administração e a direção permanecem responsáveis pelo cumprimento de todas as leis, regras e normas aplicáveis (The Joint Forum, 2005).

Conformidade e ética não devem ser apenas fazer cumprir as leis e regras. Elas também devem incluir apelos positivos para o melhor da natureza humana e o reconhecimento de que as pessoas em empresas fazem coisas boas e até heróicas, e que devem ser reconhecidos, para mostrar liderança ética (Driscoll; Hoffman; Murphy, 1998, p. 37

Silva-Sanchéz (2013, p. 192-193) analisa que a relação de vigilância e de compliance manifesta-se desde a origem da própria cultura do cumprimento normativo, enquanto expressão da delegação às empresas das funções de prevenção de ilícitos próprias do Estado. Os programas de compliance não se limitam a adoção de medidas de vigilância, mas também se integram com medidas buscam neutralizar fatos ilícitos e incentivar culturas de grupo de fidelidade ao Direito, aproximando-se a variante da prevenção geral positiva proposta por 
Welzel, no sentido de fomentar os valores ético-sociais da ação, como via de proteção indireta dos bens jurídicos.

Diante disso, indaga-se qual seria a consequência da não implantação decompliance? Em verdade, a implementação de um compliance integra a sistematização e procedimentalização formalizadas de um modelo de vigilância dos superiores sobre os subordinados, de forma que a omissão desta implantação em uma empresa que seria necessária tal vigilância poderia ensejar em uma sanção penal (para a empresa e a depender da previsão legislativa do tipo doloso/culposo), pela atuação defeituosa de um subordinado.

Diante desse contexto, a adoção dos chamados compliance officers ganha relevância, e excede a de um mero delegado de vigilância, pois tem obrigações para com a formação dos subordinados, além da supervisão.

\subsubsection{Compliance e a ética}

"O ato moral é um ato de religação: com o outro, com uma comunidade, com uma sociedade e, no limite, religação com a espécie humana" (Santos, Guevara, Amorim, FerrazNeto, 2012, p. 2). A crise ética de nossa época é o reflexo dessa crise de "religação" indivíduo/sociedade/espécie, e, por conseguinte, sua regeneração está atrelada à reconstituição desse circuito. Essa "religação" passa necessariamente pela conscientização moral do indivíduo ao despertar do contexto em que está inserido e pelo esvaziamento do seu egocentrismo. $\mathrm{O}$ indivíduo precisa, por mais difícil que seja, buscar a "autoética".

A análise do outro torna-se ainda mais necessária quando são consideradas organizações nas quais existam diversas "consciências morais" de seus membros e grupos, e isso aumenta a complexidade como sociedade. Com isso tem-se a relevância do "compliance ético" nas organizações (Santos et al 2012).

A percepção e entendimento de que a empresa está alerta à realização de possíveis atos antiéticos praticados pelos stakeholders constitui em um forte inibidor, e tende a manter elevado nível do clima ético, alcançado por esforço na adoção de programa de ética e de sua liderança. Essa percepção pode ser mais efetiva quando a empresa implementa sistema de controle e monitoramento dos ambientes internos e externos, fazendo com que as políticas que pautam a ética da empresa tenham respeito e sejam cumpridas (Nash, 1993).

De acordo com Manzi (2008), os sistemas de controle são instrumentos de acompanhamento da ética, pelo comitê, e servem como subsídio para o treinamento. Com base 
nisso, asseguram que riscos relacionados às suas atividades possam ser reconhecidos e administrados de forma adequada, além de serem utilizados por compliance, visando estimular a aderência ao código de ética.

A literatura apresentada faz um alerta para situações de impossibilidade de supersistemas de controle como ferramenta para sanar a corrupção. No entanto, a prática de compliance contribui para o enfrentamento do problema (Santos et al 2012).

Entende-se que no cerne das iniciativas de compliance também está a preocupação com a quebra da confiança no relacionamento econômico e social entre as organizações, os funcionários e os stakeholders. No entanto, a ausência de segurança e de confiança propicia um enfraquecimento das relações econômicas e sociais. Segundo Arruda, Whitaker e Ramos (2001, p. 23), "a ausência de valores morais - gera a situação atual - é o pior dos males que pode afligir o tecido social".

\subsubsection{Compliance e Governança Corporativa}

O Brasil atualmente está em um patamar que coloca compliance como um dos pilares da governança corporativa ao garantir a conformidade com normas, leis e políticas internas e externas à organização, bem como ao fortalecer o ambiente ético por meio de controles internos e aumento da transparência.“Certamente não se pode falar em governança corporativa e sustentabilidade sem se referir à ética e consequentemente considerar a importância de compliance" (Manzi, 2008, p. 123).

São elementos fundamentais de um programa de compliance a definição da atuação desta área na instituição e no relacionamento com outras áreas, bem como um plano estratégico para atender ao negócio. Entretanto, é recomendável que exista na organização um gestor de compliance, o qual terá a função de estruturar o desenvolvimento de compliance para toda a organização, atuando no processo de identificação de riscos e definição de controles, além de aderência a política internas e regulamentações (Manzi, 2008, p. 48-49).

As corporações buscam mais que indicadores de resultados, buscam repensar seus processos e investimentos com maior responsabilidade e transparência junto aos stakeholders, assim como uma melhor remuneração aos (Arnott; Asness, 2003, p. 70-87). Desta forma, a adoção dos princípios de Governança Corporativa e o Compliance tornam-se essenciais em empresas que exercem as melhores práticas de mercado (Doidge et al 2007).

Outros aspectos que precisam ser considerados são os mecanismos que mostram estatisticamente significativos quanto ao seu uso mais intenso entre as empresas que afirmam 
possuir um modelo formal de Governança de TI. Inclusive a percepção dos executivos em relação ao impacto proporcionado pelos mecanismos de governança de TI na gestão de TI foi identificado como primeiro grau em termos de importância para o gerenciamento de TI, e em segundo as práticas de compliance. Compliance foi apontada como um mecanismo de forte impacto sobre a gestão de TI, proporcionando a redução de riscos de fraude, a revisão de procedimentos, o desenvolvimento de práticas mais eficientes e uma melhor distribuição de responsabilidades (Lunardi, 2008, p.195).

A necessidade de uma governança bem definida e mais exigente dentro da organização aumenta cada vez mais com o passar do tempo. A complexidade dessas organizações requer estruturas de compliance mais elaboradas, ou seja, maior controle nos negócios e no processo de tomada de decisões. As ferramentas de apoio à governança são inovações de apoio de extrema importância para tornar as organizações mais controladas sem que deixem de ser ágeis (Bowena; Cheung; Rohdeb, 2007, p. 192). As organizações devem ser ágeis, eficientes, flexíveis e inovadoras. A inovação é um importante ativo intangível (Albertin; Albertin, 2005, p. 23-24).

Tornou-se desafiador o entendimento da Sarbanes-Oxley (SOX) de que uma inovação de compliance contribui não apenas com a governança, mas também com o processo de inovação da organização.

Kerin e Peterson (1983, p. 40), por sua vez, mencionam:

[...] o gerenciamento estratégico é a maneira de pensar que integra amplamente os pontos de vista estratégicos e operacionais e as decisões no sentido de dirigir os recursos em direção a oportunidades consistentes com as capacidades da empresa, a fim de atingir uma vantagem diferencial sustentável.

Atualmente, bancos já possuem a área de Risco Socioambiental ligada à área de Compliance para captação de clientes e manutenção de relacionamentos, até mesmo para concessão de créditos e empréstimos realizando diligências necessárias, incluindo visitas aos clientes, evitando que sejam envolvidas em projetos que apresentem grande potencial de envolvimento com problemas de degradação a natureza e a sociedade.

Há também Comitês institucionais chamados de "Comitês Verdes" que realizam debates de projetos, concessões de créditos e empréstimos de grandes portes entre os diretores executivos para tomar a melhor decisão e também para aprovar novos produtos/serviços que possam ser oferecidas ao setor de agronegócios entre outros. 


\subsubsection{Compliance e custo-benefício}

O novo Acordo da Basileia, conhecido como Basileia II, é elencado como um dos importantes instrumentos para determinar o valor de alocação de capital, e exige que banco desenvolva técnicas de gerenciamento de riscos que não podem ser quantificados. Isso significa dizer que por meio de medições quantitativas, é possível realizar a definição do nível de falhas nos controles internos que podem afetar a confiança dos investidores na instituição financeira (Manzi, 2008).

Há estudos que analisam o custo-benefício de uma implantação de programas de compliance em organizações, os quais chegaram à conclusão de que para cada U\$1,00 gastos são economizados U\$5,00 com a mitigação de processos legais, danos à reputação e perda de produtividade (Schilder, 2006, apud ManzI, 2008 p.101).

O estudo da Association of Certified Fraud Examiners, apresenta estatísticas do Federal Board of Investigation dos EUA, que indicam que um assaltante de banco levará, em uma ação, aproximadamente US\$12.000,00, com uma chance em nove de ser preso. Por outro lado, um fraudador em uma empresa levará, em média, US\$100.000,00 com uma chance em 10.000 de ser preso - e uma proporção ainda menor de que a vítima recupere os recursos subtraídos. Comportamentos sem base ética geram riscos para as empresas (Santos et al 2012).

Compliance cada vez mais é um fator diferencial para a competitividades das organizações, pois o mercado busca e valoriza a transparência e a ética nas suas interações econômicas e sociais. Para Manzi (2008), existe a possibilidade da criação de vantagem competitiva quando a organização agrega valor para a governança corporativa, com o uso de ferramentas de compliance. Essas ferramentas procuram adequar-se às melhores práticas do mercado, e podem fazer com que as empresas evoluam na lucratividade, ética, excelência e na adequação às novas realidades da concorrência. Conforme Newton (2002), no caso de haver o entendimento de que compliance representa custo para a organização, de ser caro, então, tente não estar em compliance.

\section{Metodologia}

O presente estudo foi desenvolvido dentro da Diretoria de Compliance, de uma instituição financeira Multinacional de grande porte, de origem Holandesa, com sede no Brasil, localizada na cidade de São Paulo. Até final de 2008, quando da sua venda, foi o quarto maior banco de varejo do país, com mais de 33 mil colaboradores. Tinha como estratégia e valores 
colocar sempre os clientes em primeiro lugar, e como meta criar valor de maneira sustentável e a longo prazo para todos os envolvidos, como clientes, acionistas, funcionários e a sociedade de maneira geral.

Para resguardar o sigilo da instituição financeira, objeto do presente relato técnico, o nome da instituição não será divulgado.

O objetivo desse relato técnico é descrever de forma aplicada a evolução da área de Compliance, sua importância, sua abrangência, as contribuições da existência de adequada estrutura às necessidades da Instituição e do mercado. Adicionalmente, são apresentadas as consequências da não existência da área de compliance implementada nas organizações.

Para o desenvolvimento e estruturação do relato técnico, adotou-se a observação direta e a participação direta, pois foi utilizado a experiência pessoal de um dos autores, primeiramente como ex-funcionário de uma Instituição Bancária por 18 anos, sendo 13 desenvolvendo e trabalhando na área de Compliance.

O levantamento da documentação para a realização do relato técnico foi originário de pesquisa documental (fontes primárias) e pesquisa bibliográfica (fontes secundárias). A experiência na instituição financeira possibilitou utilizar a participação e a observação diretas e a coleta de evidências por meio da bibliografia histórica de documentos, manuais, instruções, legislações, livros, artigos, entre outros, com conceitos e exemplos de aplicação, datados desde 1998 (Yin, 1989).

Este relato mostra a necessidade das Instituições Financeiras estruturarem uma área de Compliance, quais as características e deveres da área e a sua extensão dentro da específica Instituição Bancária citada nesse relato técnico. O relato destaca as contribuições de ter essa área, adequada às necessidades e exigências legais, mitigando seus riscos preventivamente e mantendo uma boa imagem junto ao mercado e aos órgãos reguladores. Apresenta também as consequências e sanções que as instituições podem ter por não possuírem a área de Compliance.

\section{Resultados obtidos e análise}

A Instituição apresentada no presente relato técnico é uma Instituição Financeira de origem Holandesa. Com a aquisição de um banco brasileiro, com sede em São Paulo, tornouse o quarto maior banco do país com mais de trinta e três mil colaboradores.

Os princípios de negócios da instituição sempre contemplaram a colocação do cliente em primeiro lugar, e com meta da instituição tem-se a criação de valor de maneira sustentável e a 
longo prazo para todos os envolvidos nas atividades (clientes, acionistas, funcionários, e as sociedade de maneira geral) (Site da instituição, 2009).

A instituição e os que dela participam vivem esses valores de maneira intensa para mostrar por meio das ações que realmente são confiáveis, profissionais e ambiciosos. Somente conseguiram colocar em prática seus princípios quando souberem como interagir com os consumidores e entre si mesmo. Por isso, para eles é importante que todos os funcionários saibam onde estão e para onde estão indo.

A abordagem com ênfase normativa (compliance-based) é mais comum em organizações tradicionais, hierárquicas e centralizadoras. Organizações mais participativas, cuja gestão enfatiza a cultura como fonte das atitudes (values-based), tendem a privilegiar ações de conscientização e educação para reforçar a ética e valores individuais.

Criou-se a área de Compliance nessa Instituição, à partir do ano de 2000. A implementação contou com estrutura não somente de atendimento às exigências legais e prevenção a lavagem de dinheiro, que se apresentava latente na época, mas também com foco preventivo, satisfazendo além do regulador, os princípios de negócios e a importância que a Instituição atribuía aos clientes, acionistas, funcionários e a sociedade de maneira geral. De acordo com a Resolução 2554/98, do Bacen, o seu artigo $4^{\circ}$ incube a diretoria da instituição, a promoção de elevados padrões éticos e de integridade e de uma cultura organizacional que demonstre e enfatize, a todos os funcionários, a importância dos controles internos (BACEN, 2015).

A instituição criou metodologias que atendessem essa necessidade de prevenção dos riscos, conscientização e educação sobre ética e valores, disseminando a "cultura de compliance" a cada colaborador, tornando-os representantes de compliance em sua área, diretoria e empresa ligada. Esses métodos foram ao encontro de negócios transparentes, confiáveis e sustentáveis da Instituição em questão, que até então não tangibilizava, não mensurava as ações pró-ativas realizadas, ou as penalidades por não tê-las. Mais importante ainda, foi possível, por meio das ações, equilibrar o entendimento e avaliação de riscos entre compliance e a área de negócios.

No Reino Unido (STATUTORY INSTRUMENT - THE MONEY LAUDERING REGULATION,2003) e nos EUA (Sarbanex Oxley, 2002), já vigoram normas específicas que determinam a responsabilidade dos dirigentes, funcionários e consultores pelos controles para a prevenção à lavagem de dinheiro no exercício do seu ofício. 
No Brasil, a redação da Lei ${ }^{\circ}$ 9613-98 é clara e estabelece neste caso, em havendo ocultação de patrimônio de origem ilícita, consciente de espontânea inobservância de algum dos deveres de colaboração anti-lavagem, enseja a responsabilidade dos dirigentes, funcionários e consultores, por crime de lavagem de dinheiro, podendo responder por dolo direto ou eventual, sob pena de até mesmo serem impedidas de exercerem suas atividades, sofrerem danos à sua imagem ou ainda sanções às organizações (podendo gerar processos administrativos ou até mesmo criminais) (Magalhães, 2014, p. 181).

No ano de 2005, as autoridades federais do EUA multaram em US\$ 80 milhões esta Instituição no seu país, por violar as leis contra lavagem de dinheiro. A multa foi uma das maiores impostas no setor bancário americano. A instituição, que concordou com a multa, trouxe diversas das violações à atenção das autoridades após descobri-las em investigação interna. As autoridades acusaram o banco de falha no monitoramento de atividades suspeitas, negligência na comunicação de incidentes suspeitos, falha a investigação dos clientes (The Wall Street Journal, 2005).

Ressalta-se que a unidade no Brasil, nunca teve problemas com os reguladores, além do excelente relacionamento, servindo de exemplo por vezes nas entidades de classe, por conta do Sistema de controles internos e de compliance adotados. Os indicadores de reclamações, processos, multas, sempre foram muito baixos, em relação aos apresentados no mercado de bancos, sequer faziam parte do ranking negativo publicado ao mercado (até final de 2008, quando da venda da Instituição).

Como contribuição relevante, que pode ser destacada pelo relato está a motivação para a adoção de compliance pela instituição financeira. O grande destaque para essa motivação, entre outros, é aspectos relacionados à corrupção/fraude, em suas várias formas. A instituição estava segura e tinha as suas convicções de que a corrupção e fraude provocavam grandes prejuízos financeiros, sentidos de forma imediata.

Esse ponto deve ser levado em conta por outras instituições financeiras e empresas no país, além de considerado como um importante ensinamento profissional, devido ao impacto das corrupções e fraudes, tanto para o ambiente interno como para o externo às instituições.

A importância da prevenção de riscos, de acordo com Manzi (2008), é tão considerável que o novo Acordo da Basileia, a elenca como uma das principais ferramentas para determinar o valor de alocação de capital, ou seja, por meio de medições quantitativas, é possível definir o 
grau de falhas nos controles internos que podem afetar a confiança dos investidores na instituição financeira.

Cabe destacar que a inexistência da área de compliance tende a favorecer um ambiente para a ocorrência, com maior freqüência, de fraudes e corrupções, que impactam em outras importantes questões:

- destroem a imagem e a reputação de qualquer organizações;

- comprometem o bom ambiente de trabalho;

- esgarçam a sociedade;

- aumentam os custos de investimento, e

- alimentam condutas nocivas para o desenvolvimento econômico e social.

Pelos nossos acompanhamentos e integração com os reguladores e entidades de classe, temos certeza que a nossa intervenção estruturando, criando metodologias e formas de acompanhar e alertar preventivamente as áreas, reformulação de processos, gestão de pessoas e de todos os envolvidos foi o que culminou, de forma positiva, a disseminação da "cultura de compliance".

Destaca-se ainda que a intervenção dos gestores da implementação de compliance na instituição financeira estudada, com as suas ações e conscientização produziam efeitos multiplicadores, que tornavam cada funcionário como representante de compliance em suas atividades, área e diretoria. Essas ações estão em conformidade com Laruccia e Yamada (2013) que mencionam que a missão de uma área de Compliance em uma instituição está voltada a assegurar a existência de políticas e normas, ainda pontos de controle no processo a mitigar riscos.

A criação de representantes de compliance em cada uma das áreas possibilitou a implementação de pontos de controle em cada uma das áreas da instituição, e sem dúvida, trouxe redução dos riscos. Há necessidade das Instituições Financeiras estruturarem uma área de Compliance adequada às necessidades e exigências legais, mitigando seus riscos preventivamente e mantendo uma boa imagem com o mercado e os Órgãos Reguladores.

O relato sobre a implantação do compliance pela instituição financeira pode ser exemplo e fonte de inspiração e motivação para outras instituições de menor porte e, até mesmo outras organizações, seguirem a mesma trajetória de sucesso.

\section{Considerações finais}


O objetivo desse relato técnico é descrever de forma aplicada a evolução da área de Compliance, sua importância, sua abrangência da área, as contribuiçõos da existência de adequada estrutura às necessidades da Instituição e do mercado. Adicionalmente, são apresentadas as consequências de não ter a área de compliance, implementadas nas organizações.

Os dados aqui apresentados confirmam que a organização necessariamente precisa buscar o compliance como meio de fortalecer sua posição no mercado, e a sociedade precisa encarar a ética não só como uma forma de ação conveniente, mas também como uma condição de sobrevivência da sociedade.

Um risco de mensurar a adoção de compliance é a não correlação do custo-benefício de sua implantação com o retorno esperado, porque riscos reputacionais encontram dificuldade de mensuração. Enfim, compliance não é uma questão financeira, mas uma questão de princípios (Schilder, 2006, apud Manzi, 2008, p.99).

Relatou-se que as motivações para a adoção de compliance nas organizações são várias. A corrupção/fraude, em suas várias formas, provoca prejuízos financeiros imediatos, destrói a imagem e a reputação das organizações, estraga o ambiente de trabalho, esgarça a sociedade, aumenta os custos de investimento, e alimenta condutas nocivas para o desenvolvimento econômico e social. Ao contrário do que análises economicistas sugerem, a confiança entre os agentes está na base dos negócios: a maior parte das transações econômicas não são sustentadas por supersistemas de segurança, mas pela confiança. Um sistema de controle infalível, se existisse, seria mais caro do que o benefício potencial da vigilância (Santos et al, 2012, p. 2).

Os dados também apontam para a maior sensibilidade do líder à transgressão das normas de compliance e, simultaneamente, para a maior lealdade com a organização. Por exercer o poder, o líder está exposto de forma mais intensa às escolhas que envolvem dilemas éticos, suas ações têm maiores consequências sobre o grupo, e suas responsabilidades são maiores. Se o comportamento do líder é fortemente influenciado pelo contexto, ou fortuna, as pressões pelos resultados e a cultura organizacional permissiva, não ajudam os comportamentos éticos.

É importante o exemplo dos líderes, a proposta da organização-instituição, pois se não houver a intenção verdadeira sobre o cumprimento das regras, dos controles e da disseminação desses entre os envolvidos, os sistemas de controles nunca serão suficientes para impedir a generalização de condutas inadequadas, ou até mesmo corruptas. 
"A ética, como toda emergência, depende das condições sociais e históricas que a fazem emergir. Mas é no indivíduo que se situa a decisão ética; cabe a ele escolher os seus valores e as suas finalidades" (Morin, 2004, p. 29). A confiança é, de todo modo, ingrediente muito importante quando se implementam ações de controles. Se cultura organizacional é displicente quando a ética e lealdade se combinam, os resultados nas condutas individuais podem ser desastrosos para a organização a médio e longo prazos.

$\mathrm{O}$ aspecto limitante do trabalho é a experiência relatada em apenas uma Instituição Financeira, não sendo abordado um conjunto de vantagens, inclusive de forma comparativa, em outras Instituições.

Espera-se que outros profissionais se sintam motivados a relatar as experiências que tiveram e vivenciaram em outras instituições financeiras, tanto no que se refere ao compliance como também outras experiências, que possam contribuir com a formação profissional.

\section{Referências}

Albertin, L. A; Albertin, R. M. M. (2005). Tecnologia de Informação: Desafios da tecnologia de informação aplicada aos negócios. São Paulo: Atlas.

Acref - Limites e responsabilidades dos profissionais de compliance, vol.1, 2010.

Arnott, R.D.; Asness, C. S. (2003). Surprise! Higher dividends=higher earnigs growth. Financial Analysts Journal, p.70-87.

Arruda, Maria Cecília Coutinho de; Whitaker, Maria do Carmo; Ramos, José Maria Rodrigues Ramos. (2001). Fundamentos de Ética Empresarial e Econômica. São Paulo: Atlas.

Bacen - Banco Central do Brasil. Lei $n^{o}$ 9613/98 e Resolução $n^{o}$ 2554/98. Disponível em: <www.bcb.gov.br>. Acesso em: set. 2015.

Bittencourt, Sidney. (2014). Comentários à Lei Anticorrupção: Lei 12.846/2013. São Paulo: Editora Revista dos Tribunais.

Bowena, Paul L.; Cheung B, May-Yin Decca; Rohdeb, Fiona H. (2007). Enhancing IT governance practices: A model and case study of an organization's efforts. International Journal of Accounting Information Systems. v. 8, p. 191-221, 2007.

CENP - Conselho Executivo de Norma Padrão - Documentos de orientação ética I (2014).

Doidge, C., Karolyi, G. Andrew; Stulz, R. M. (2007). Why do countries matter so much for corporate governance. Journal of Finance Economics, v. 86, n. 1, p. 1-39.

Driscoll, Dawn-Marie; Hoffman, W. Michael; Murphy, Joseph E. (1998). Business ethics and compliance: What management is doing and why. Business and Society Review, v. 99, n. 1, p. 35-51.

Federação Brasileira de Bancos. Documento Consultivo: Função de Compliance. Grupo de Trabalho ABBI-FEBRABAN. Disponível em: <http://www.febraban.com.br>. Acesso em: set. 2015.

IIA - The Institute of Internal Auditors. Normas para a Prática Profissional de Auditoria Interna, 2001. Disponível em: <http://www.theiia.org>. Acesso em: set. 2015.

Kerin, R. A; Peterson, R. A. (1983). Perspectives on strategic marketing management. 2. ed. Boston: Allyn and Bacon. 
Laruccia, M.M.; Yamada, K. J. (2013). O desenvolvimento sustentável e a gestão de compliance em instituições financeiras. Revista Estratégica, v. 11, n. 2.

Lunardi, Guilherme. (2008). Um Estudo empírico e analítico do impacto da Governança de TI no desempenho organizacional, 2008.

Magalhães Vladimir Costa. (2014). Breves notas sobre lavagem de dinheiro. EMERJ, Rio de Janeiro, v. 17, n. 64, p. 164-186.

Manzi, Vanessa Alessi. (2008). Compliance no Brasil: consolidação e perspectivas. São Paulo: Saint Paul.

Morin, Edgar. (2003). O Método 5: Poderes e fragilidades da consciência. Porto Alegre: Sulina.

Nash LL. (1993). Ética nas empresas: boas intenções à parte. São Paulo: Makron Books.

Newton, Andrew. (2002). The Hand-book of Compliance - making ethics work in financial services. The edition publishied by Mind into Matter.

Santos R. A.; GUevara A. J.;Amorim M. C.; Ferraz-Neto, B. (2012). Compliance and leadership: the susceptibility of leaders to the risk of corruption in organizations. Einstein (São Paulo), v. 10, n. 1, p. 1-10.

Schilder, Arnold. (2006). Banks and the compliance challenge. Speech by the Professor Arnold Schilder, Chairmain of the BCBS Accounting Task Force and Executive Director of the Governing Board of the Netherlands Bank, at the Asian Banker Summit, Bangkok, 16 March 2006.

Silva, André Vinicius. (2008). Arbitragem e fraudes financeiras: os casos do Banco Barings e do Banco Societé Générale, 2008. Monografia - UNICAMP.

Silva-SAnchéz, Jesús María. (2013). Fundamentos del Derecho Penal de la Empresa. Editora: B de F.

Tarantino, G. Anthony. (2006). Manager's guide to compliance: Sarbanes-Oxley, COSO, ERM, COBIT, IFRS, BASEL II, OMB A-123, ASX 10, OECD principles, Turnbull guidance, best practices, and case. John Wiley \& Sons.

The Joint Forum (i.e. the Basel Committee on Banking Supervision, the International Organization of Securities Commissions, and the International Association of Insurance Supervisors 2005).

Yin, R. K. (1989) Case study research: design and methods. Newbury Park, CA: Sage Publications. 